NOAA

National Marine

Fisheries Service
Fishery Bulletin

2 established 1881 ๙
Spencer F. Baird

First U.S. Commissione of Fisheries and founder of Fishery Bulletin
Abstract-Most of the drifting fish aggregating devices (DFADs) used in industrial tropical tuna purseseine fisheries are equipped with satellite linked echosounder buoys, which provide fishing crews with remote, accurate geolocation information and rough estimates of FADassociated tuna biomass. One of the most common brands of echosounder buoys (SATLINK, Madrid, Spain) is currently calibrated for the target strength of skipjack tuna (Katsuwonus pelamis) and provides biomass data on that species. Using that brand of echosounder buoy, we developed a new behavior-based approach to provide relative biomass estimates and a remote target classification of fish aggregations at FADs. The model is based on current knowledge of the vertical distribution of the main fish species associated with FADs, as well as on appropriate TS and weight values for different species and sizes, and is further based on parameter optimization against a set of fishing operations on DFADs. This model reduced the error variability in biomass estimates by about $60 \%$ and also reduced the ranges of underestimation and overestimation by $55 \%$ and $75 \%$, respectively. Similarly, the original coefficients of correlation and determination were also considerably improved from 0.50 and 0.25 to 0.90 and 0.82 , respectively. We discuss how this new method opens new opportunities for scientific studies and has implications for sustainable fishing.

Manuscript submitted 14 August 2015. Manuscript accepted 29 January 2016. Fish. Bull. 114:166-178 (2016).

Online publication date: 23 February 2016 doi: $10.7755 /$ FB.114.2.4

The views and opinions expressed or implied in this article are those of the author (or authors) and do not necessarily reflect the position of the National Marine Fisheries Service, NOAA.

\title{
A model based on data from echosounder buoys to estimate biomass of fish species associated with fish aggregating devices
}

\author{
Jon Lopez ${ }^{1}$ \\ Gala Moreno ${ }^{1,3}$ \\ Guillermo Boyra' \\ Laurent Dagorn² \\ Email address for contact author: jlopez@azti.es \\ ${ }^{1}$ AZTI-Tecnalia \\ Herrera kaia \\ portualdea $z / g$ \\ 20110 Pasaia (Gipuzkoa), Spain \\ 2 Institut de Recherche pour le Développement \\ IRD, UMR EME 212 \\ Avenue Jean Monnet \\ CS 30171 \\ 34203 Sète Cedex, France \\ 3 International Seafood Sustainability Foundation (ISSF) \\ 805 15th Street NW \\ Washington, D.C. 20005
}

Objects floating on the surface of the tropical and subtropical oceans attract a number of marine species, including tropical tunas (Castro et al., 2002; Taquet et al., 2007b). Taking advantage of this associative behavior, tropical tuna purse seiners regularly deploy drifting, manmade floating objects, also called drifting fish aggregating devices (DFADs), to facilitate their catch of skipjack (Katsuwonus pelamis), yellowfin (Thunnus albacares) and bigeye (Thunnus obesus) tunas. This fishing method is essential for the current operation of purse-seine fleets in all oceans; more than 50\% of purse-seine sets (and greater than $70 \%$ of purse-seine sets during some years in the Indian and eastern Pacific Oceans) are made on floating objects. This method accounts for nearly half of the world's tropical tuna catch (Dagorn et al., 2013).
Indeed, it has been estimated that 50,000-100,000 DFADs are deployed annually worldwide (Baske et al.1; Scott and Lopez ${ }^{2}$, which drift at sea on average for periods of over one or two months depending on the ocean (Maufroy et al., 2015). However, the increasing use of DFADs has led to concerns. Setting on floating objects contributes to the catch of small and undesirable sizes of bigeye and yellowfin tuna that are usually not caught by sets on free-swimming

${ }^{1}$ Baske, A., J. Gibbon, J. Benn, and A. Nickson. 2012. Estimating the use of drifting fish aggregation devices (FADs) around the globe, 8 p. PEW Environmental Group, 901 E Street NW, Washington, D.C. 20004. [Available at website.]

2 Scott, G. P., and J. Lopez. 2014. The use of FADs in tuna fisheries. European Union, European Parliament, Policy Department B: Structural and Cohesion Policies, Fisheries IP/B/PECH/IC/2013123,70 p. [Available at website.] 
schools (Fonteneau et al., 2013). In addition, while encircling tunas associated with a DFAD, purse seiners also enclose nontarget species that are associated with the object and thus increase the bycatch-to-catch ratio in comparison with ratios obtained from setting on free-swimming schools.

Today, many DFADs are equipped with satellitelinked echosounder buoys (Lopez et al., 2014), which provide fishermen with remotely collected rough estimates of the DFAD-associated tuna biomass, as well as accurate geolocation information. Fishing crews use the biomass estimates from the buoys, along with other information (e.g., environmental conditions from remote sensing data, catches by other vessels in the same area), to decide on the best DFAD to visit next. A biomass estimate provided by an echosounder buoy is represented by a single value and does not comprise information on species composition (tuna and nontuna) nor the size distribution of the aggregation. Fishermen obtain information only on the size and species composition of the aggregations after setting on the floating device and the catch is hauled on deck. Therefore, fishing crews cannot currently use echosounder buoys to remotely assess the catch composition (biomass of every species and size category) before deciding on which DFAD they will set a course.

On the other hand, scientists have been studying fish aggregations at DFADs using various observation techniques such as active acoustic tracking (Matsumoto et al., 2014), passive acoustic tracking (Taquet et al., 2007a; Filmalter et al., 2011; Schaefer and Fuller, 2013; Matsumoto et al., 2014), scientific acoustic surveys (Moreno et al., 2007), and underwater visual census (Taquet et al., 2007b). Clearly, scientific knowledge on the behavior of DFAD-associated aggregations is currently limited by the cost of accessing and working on remote DFADs. Developing autonomous observation tools that can be attached to DFADs for continuous direct long-term monitoring of fish aggregations has been a challenge in recent years (Dagorn et al., 2007a). Therefore, echosounder buoys used extensively by fishermen appear to be a powerful tool for observing fish aggregations at DFADs remotely in a cost-effective manner. However, there is currently no satisfactory buoy that can provide reliable information on the abundance and sizes of the different species that compose these fish aggregations. The lack of reliable information precludes gaining a better understanding of the behavioral processes involved in the dynamics of these aggregations.

The objective of this study was to develop a new processing method for data collected by one of the brands of echosounder buoys used by tropical tuna purse seiners, by using data on the vertical distribution of the different fish species and fish sizes at FADs, their corresponding target strength (TS, $\mathrm{dB}$ re $1 \mathrm{~m}^{2}$; MacLennan et al., 2002) and weight values, and further parameter optimization against the data from a set of fishing operations on DFADs.

\section{Materials and methods}

\section{The buoy}

At the start of this study, three companies were manufacturing echosounder buoys for DFAD fishing. Echosounder specifications (frequency, beam width, depth range, etc.), and the algorithms used to convert acoustic backscatter into biomass values differ between companies. Twenty-four Spanish tropical tuna purse seine skippers were interviewed to collect data on echosounder buoy usage, display quality, and reliability of different brands. Manufacturers were also contacted to obtain technical information on their products. On the basis of all available information, the Satlink buoy (SATLINK, ${ }^{3}$ Madrid, Spain, website) was selected for the purpose of the present study.

The buoy contains a Simrad ES12 echosounder, which operates at a frequency of $190.5 \mathrm{kHz}$ with a power of $140 \mathrm{~W}$ (beam angle at $-3 \mathrm{~dB}: 20^{\circ}$ ). The sounder is programmed to operate for 40 seconds. During this period, 32 pings are sent from the transducer and an average of the backscattered acoustic response is computed and stored in the memory of the buoy's software program (hereafter called "acoustic sample"). Volume backscattering strength $\left(\mathrm{S}_{\mathrm{v}}, \mathrm{dB}\right.$ re $1 \mathrm{~m}^{-1}$; MacLennan et al., 2002) values smaller than $-45 \mathrm{~dB}$ are automatically removed by the internal module of the buoy, as a precautionary measure to eliminate signals that likely correspond to organisms smaller than tuna (e.g., organisms of the sound scattering layers; Josse et al., 1998; Josse and Bertrand, 2000). The observation depth range extends from 3 to $115 \mathrm{~m}$ (with a blanking zone [a data exclusion zone to eliminate the nearfield effect of the transducer; Simmonds and MacLennan, 2005] from 0 to $3 \mathrm{~m} \mathrm{depth)} \mathrm{and} \mathrm{is} \mathrm{composed} \mathrm{of} 10$ homogeneous layers, each with a resolution of $11.2 \mathrm{~m}$ (Fig. 1). Because echosounder buoys belonged to fishing crews, they were not calibrated at the deployment site; instead, they were calibrated by manufacturers in tanks before delivery.

Raw acoustic data are provided for each depth layer and were originally converted to biomass (in metric tons, [t]) by using an experimental algorithm developed by the manufacturer, which is based on the TS of skipjack tuna, the main target species of the fleet fishing around DFADs. This conversion is automatically executed in the internal module of the buoy for each integrated layer $(n=1,2, \ldots, 10)$ by means of a depth layer echo-integration procedure (Simmonds and MacLennan, 2005), with the assumption that there was the presence of only individuals of skipjack tuna of identical weight (for confidentiality reasons, authors of this article are not allowed to describe some of the proprietary technical information regarding the echosounder buoy. Readers interested in more technical de-

\footnotetext{
${ }^{3}$ Mention of trade names or commercial companies is for identification purposes only and does not imply endorsement by the National Marine Fisheries Service, NOAA.
} 
A

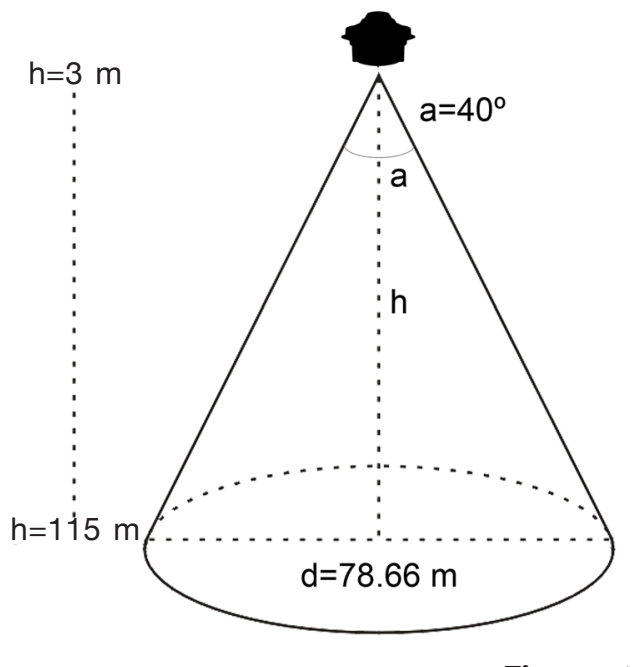

B

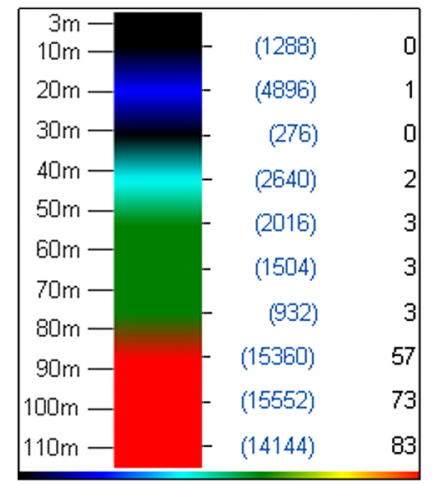

Figure 1

(A) Beam width [or angle] (a), depth range (h), and diameter (d) at $115 \mathrm{~m}$ of the Satlink echosounder buoy. (B) An example of the echogram display for the 10 depth layers (ranging from $3 \mathrm{~m}$ to $115 \mathrm{~m}$ ): raw acoustic backscatter (numbers between parentheses) and their corresponding biomass estimates in metric tons (numbers in black) for skipjack tuna (Katsuwonus pelamis) based on the manufacturer's algorithms. The acoustic information used in this study was collected by a commercial Spanish purse seiner operating in the central and eastern Atlantic Ocean between 2009 and 2011.

tail about this process should contact the manufacturer directly).

\section{The model}

Because the manufacturer's method is not designed to provide abundance estimates for the different species and sizes of fish that usually compose fish aggregations at DFADs (Fonteneau et al., 2013), we proposed a new method consisting of developing specific algorithms by ocean or regional sites. The specificities of the regional algorithms would be based on 1) existing knowledge of the vertical behavior of fish at FADs, 2) appropriate TS and weight values for different species and sizes to perform a multispecies and size echo-integration, and 3) further parameter optimization against a set of fishing operations on DFADs of each region. In the present study, and as an example of application of the method, we developed a specific algorithm for DFADs in the Atlantic Ocean using a set of 21 fishing sets.

Assigning a species group to each depth layer Knowing the vertical distribution of species within the observational range of the buoy is essential for accurately converting acoustic backscatter into biomass of different fish groups. For that purpose, we reviewed all available scientific studies focused on the investigation of the behavior of tuna and nontuna species when associated with FADs (Brill et al., 1999; Musyl et al., 2003;
Schaefer and Fuller, 2005; Matsumoto et al.4; Dagorn et al., 2007b; Dagorn et al., 2007c; Taquet et al., 2007a, 2007b; Babaran et al., 2009; Leroy et al., 2009; Govinden et al. ${ }^{5}$; Filmalter et al., 2011; Mitsunaga et al., 2012; Muir et al.6; Govinden et al., 2013; Schaefer and Fuller, 2013; Weng et al., 2013; Matsumoto et al., 2014; Forget et al., 2015), as well as on the spatial distribution of the echo-traces recorded around DFADs during scientific acoustic surveys (Moreno et al., 2007). Additional information was obtained from 25 echosounder buoys deployed in the Indian Ocean between 2009 and 2012 (a total of about 2000 acoustic samples). The plot

\footnotetext{
${ }^{4}$ Matsumoto, T., H. Okamoto, and M. Toyonaga. 2006. Behavioral study of small bigeye, yellowfin and skipjack tunas associated with drifting FADs using ultrasonic coded transmitter in the central Pacific Ocean. Scientific committee, second regular session. Western and Central Pacific Fisheries Commission Inf. Pap. WCPFC-SC2-2006/FT IP-7, 25 p. [Available at website.]

5 Govinden, R., L. Dagorn, M. Soria, and J. Filmalter. 2010. Behaviour of tuna associated with drifting fish aggregating devices (FADs) in the Mozambique Channel. Indian Ocean Tuna Commission (IOTC), Working Party Tropical Tuna (WPTT) IOTC-2010-WPTT-25, 22 p. [Available at website.]

${ }^{6}$ Muir, J., D. Itano, M. Hutchinson, B. Leroy, and K. Holland. 2012. Behavior of target and non-target species on drifting FADs and when encircled by purse seine gear. Scientific committee, eigth regular session. Western and Central Pacific Fisheries Commission Inf. Pap. WCPFC-SC8-2012 EB-WP-13, 7 p. [Available at website.]
} 


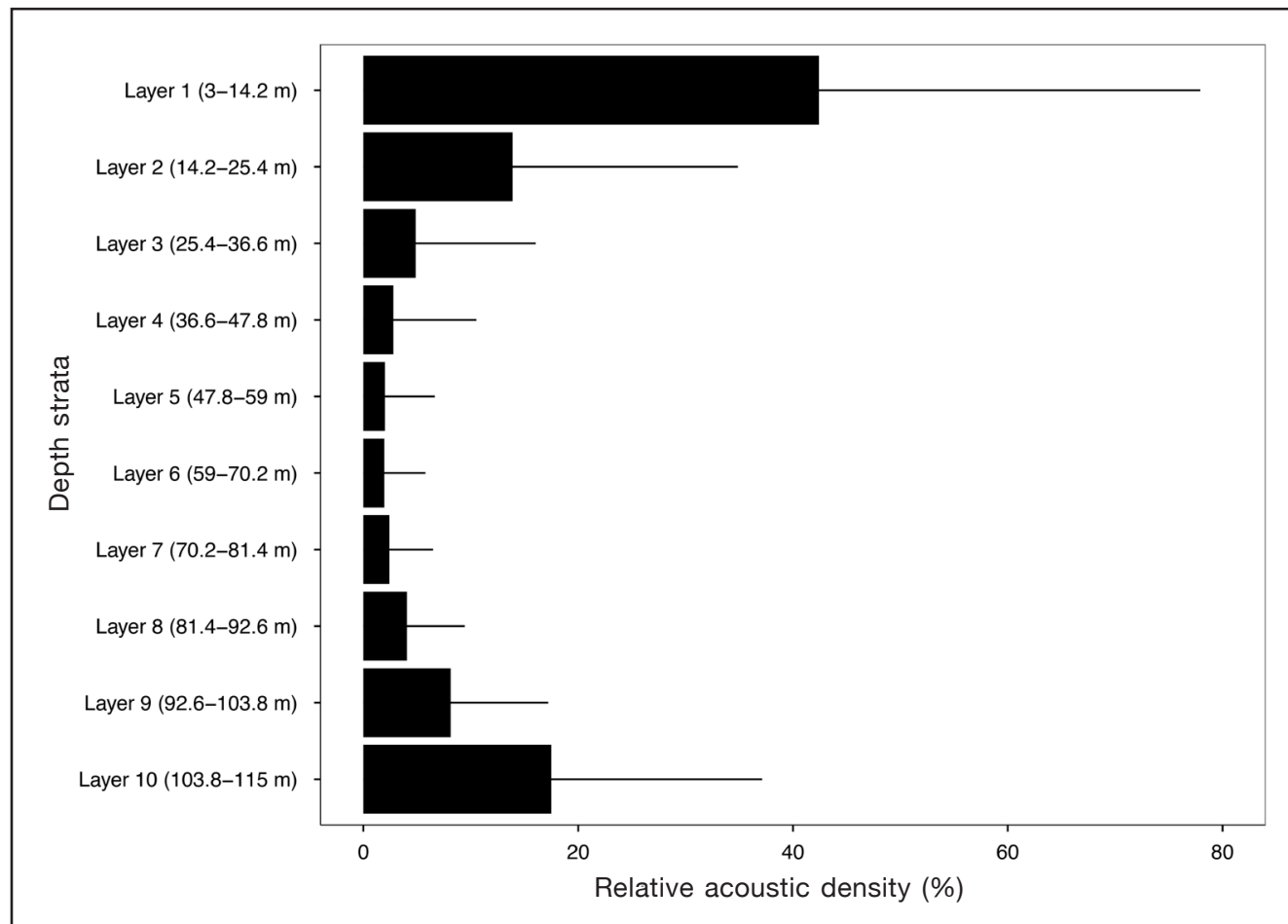

Figure 2

Average percentages of acoustic backscatter (black bars) and their standard deviations (lines) recorded at sunrise from about 2000 acoustic samples recorded by 25 Satlink echosounder buoys attached to drifting fish aggregating devices (DFADs) in the Indian Ocean between 2009 and 2012. This information was used as complementary information to define the preliminary depth limits between the different fish groups present at DFADs. The figure indicates a potential segregation of size increasing with depth and a greater likelihood of larger tuna occupying waters deeper than $80 \mathrm{~m}$ (individuals with swim bladders). The large amount of acoustic backscatter recorded in the first $25 \mathrm{~m}$ could be due to the presence of nontuna species, which also have swim bladders. Skipjack tuna, Katsuwonus pelamis, the main target species of the fleet fishing around DFADs is usually known to occupy medium depths and has no swim bladder. This potential segregation of size increasing with depth has also been found in previous works with conventional scientific echosounders around DFADs (Moreno et al., 2007).

of the average acoustic backscatter recorded by each echosounder buoy depth layer (Fig. 2), combined with the behavioral information in the references cited above, suggested a potential segregation of tuna size increasing with depth, indicating a greater likelihood of larger tuna occupying waters deeper than $80 \mathrm{~m}$. This seems to be in agreement with previous findings obtained through conventional scientific echosounders around DFADs (Moreno et al., 2007).

From this accumulated information, the vertical boundary between nontuna species and small tunas was set at $25 \mathrm{~m}$. Similar depth limits were adopted in previous studies with the use of the same echosounder buoys to separate bycatch from tuna (Lopez et al. ${ }^{7}$; Robert et al., 2013). Because vertical depth limits

\footnotetext{
${ }^{7}$ Lopez, J., G. Moreno, M. Soria, P. Cotel, and L. Dagorn. 2010. Remote discrimination of by-catch in purse seine fishery using fisher's echo-sounder buoys. Indian Ocean Tuna Commission (IOTC), Working Party Ecosystem Bycatch
}

between small and large tunas may be vague, a preliminary limit was initially set at $80 \mathrm{~m}$ depth, and was then re-adjusted in agreement with a set of 21 purse seine fishing operations conducted on DFADs in the Atlantic Ocean (see Parameter optimization section).

Assigning TS and weights values to each species group Selecting appropriate TS and weight values for different species is also crucial for adequately converting acoustic backscatter into reliable biomass estimations, by species or fish groups. Because no specific TS/ fork length (FL) relationship was available in the literature for nontarget species, we considered a TS value of $-42 \mathrm{~dB}$ for the entire group based on previous field studies (Josse et al., 2000; Doray et al., 2006; Doray et al., 2007; Lopez et al. ${ }^{7}$ ). The mean weight used for the biomass characterization of this community was $1 \mathrm{~kg} /$ ind, which was estimated from the mean length of most

(WPEB) IOTC-2010-WPEB-03, 14 p. [Available at website.] 


\section{Table 1}

Target strength (TS), acoustic backscattering cross-section $\left(\sigma_{\mathrm{bs}}\right.$, TS in linear scale) and weight (w) parameters used by the proposed method to conduct the echo-integration for each group of fish considered in this study. Below are the coefficients of correlation $(r)$ and determination $\left(r^{2}\right)$ between the uncorrected predicted biomass and real catches depending on the depth limit that was set to separate small and large tunas.

\begin{tabular}{|c|c|c|c|c|c|c|c|c|c|}
\hline & $\begin{array}{l}\text { Non- } \\
\text { tunas }\end{array}$ & $\begin{array}{l}\text { Small } \\
\text { tunas }\end{array}$ & & $\begin{array}{l}\text { Large } \\
\text { tunas }\end{array}$ & & & & & \\
\hline $\mathrm{TS}\left(\mathrm{dB}\right.$ re $\left.1 \mathrm{~m}^{2}\right)$ & -42 & -35.1 & & -29.9 & & & & & \\
\hline$\sigma_{\mathrm{bs}}\left(\mathrm{m}^{2}\right)$ & $6.3110^{-5}$ & $3.0910^{-4}$ & & $1.0210^{-3}$ & & & & & \\
\hline $\mathrm{W}(\mathrm{kg})$ & 1 & 2 & & 21 & & & & & \\
\hline Depth limit (m) & 25 & 36 & 47 & 59 & 70 & 80 & 92 & 104 & 115 \\
\hline$r$ & 0.85 & 0.84 & 0.84 & 0.84 & 0.74 & 0.74 & 0.75 & 0.76 & 0.85 \\
\hline$r^{2}$ & 0.73 & 0.70 & 0.71 & 0.71 & 0.54 & 0.54 & 0.57 & 0.58 & 0.73 \\
\hline
\end{tabular}

represented nontuna species at DFADs, and their corresponding weights (i.e., $72 \mathrm{~cm} \mathrm{FL}$ for dolphinfish [Coryphaena hippurus], $100 \mathrm{~cm}$ FL for wahoo [Acanthocybium solandri], $30 \mathrm{~cm}$ FL for triggerfish [Canthidermis maculata], and $54 \mathrm{~cm} \mathrm{FL} \mathrm{for} \mathrm{rainbow} \mathrm{runner} \mathrm{[Elegatis}$ bipinnulata] [Forget $\left.{ }^{8}\right]$ ).

Moreno et al. (2007) analyzed the spatial distribution of the TS of fish aggregations around DFADs. Because the study of Moreno et al. (2007) is the only study conducted around DFADs with conventional scientific echosounders, to determine our tuna depth layers we used the TS values found by Moreno et al. (2007) (-35.1 dB for acoustic structures found between 20 and $80 \mathrm{~m}$; and $-29.9 \mathrm{~dB}$ for acoustic structures found between 80 and $100 \mathrm{~m}$ ), which fitted reasonably well with the range of observations we initially proposed for small and large tunas. According to the most common tuna sizes caught at DFADs (Delgado de Molina et al. ${ }^{9}$; IATTC, 2013; Chassot et al. ${ }^{10}$; Floch et al. ${ }^{11}$; Fonteneau et al., 2013; Harley et al. ${ }^{12}$ ), the depth

${ }^{8}$ Forget, F. 2012. Personal commun. Institut de Recherche pour le Développement (IRD), UMR EME 212, Ave. Jean Monnet, CS 30171, 34203 Sète Cedex, France

${ }^{9}$ Delgado de Molina, A., J. C. Santana, J. Ariz, and I. Sabaté. 2012. Estadísticas Españolas de la pesquería atunera tropical, en el Océano Atlántico, hasta 2010. Collect. Vol. Sci. Pap. ICCAT 68:1200-1220. [Available at website.]

${ }^{10}$ Chassot, E., A. Delgado de Molina, C. Assan, P. Dewals, P. Cauquil, J. J. Areso, D. M. Rahombanjanahary, and L. Floch. 2013. Statistics of the European Union and associated flags purse seine fishing fleet targeting tropical tunas in the Indian Ocean 1981-2012. Indian Ocean Tuna Commission (IOTC), Working Party Tropical Tuna (WPTT) IOTC2013-WPTT15-44, 28 p. [Available at website.]

${ }^{11}$ Floch, L., A. Damiano, A. Tamegnon, P. Cauquil, P. Chavance, I. Terrier, and E. Chassot. 2014. Statistics of the French purse seine fishing fleet targeting tropical tunas in the Atlantic Ocean (1991-2012). Collect. Vol. Sci. Pap. ICCAT 70:2669-2692. [Available at website.]

${ }^{12}$ Harley, S., P. Williams, S. Nicol, and J. Hampton. 2013. The western and central Pacific tuna fishery: 2011 overview and status of stocks, 31 p. Secretariat of the Pacific Community, Noumea, New Caledonia. [Available at website.] range between 25 and $80 \mathrm{~m}$ was considered to be populated by skipjack, yellowfin and bigeye tuna of a mean mass of $2 \mathrm{~kg} /$ ind (about $50 \mathrm{~cm} \mathrm{FL}$ ), whereas the depth between 80 and $115 \mathrm{~m}$ was assumed to be populated by larger yellowfin and bigeye tuna individuals with a mean weight of $21 \mathrm{~kg} /$ ind (110-100 cm FL, for yellowfin and bigeye tuna, respectively).

Echo-integration Area backscattering coefficients $\left(\mathrm{s}_{\mathrm{a}}\right.$, $\mathrm{m}^{2} / \mathrm{m}^{2}$; MacLennan et al., 2002) recorded in each of the ten echosounder buoy layers were converted into biomass following a depth layer echo-integration procedure. A specific acoustic backscattering cross-section value $\left(\sigma_{\mathrm{bs}}, \mathrm{m}^{2}\right.$, TS in linear scale; MacLennan et al., 2002) was used to obtain the number of individuals for each of the integrated layer $(n=1,2, \ldots, 10)$ according to the presence of each group initially assigned in this study to each depth layer (i.e., nontuna [3-25 m], small tuna [25-80 m], large tuna [80-115 m]). The $\sigma_{\mathrm{bs}}$ and weight values used for the echo-integration of the acoustic backscatter are shown in Table 1 . The number of fish per group and layer $(N[n, g r])$ were estimated as follows:

$$
N(n, g r)=\frac{\mathrm{s}_{\mathrm{a}}(n)}{\sigma_{\mathrm{bs}(\mathrm{gr})}} \cdot A(n)
$$

where $\mathrm{s}_{\mathrm{a}}(n)=$ the TVG-corrected (time-varied-gain, a correction function to compensate the signal for spreading and absorption losses; Simmonds and MacLennan, 2005) area backscattering coefficient (Maclennan et al., 2002) in each layer $(n)$;

$\sigma_{(\mathrm{bs}(\mathrm{gr}))}=$ the mean TS of a known group (i.e., of nontuna species, small or large tunas) in linear scale; and

$A(n)=$ the mean cross sectional area sampled by the beam of the cone for each layer $(n)$.

Then, the total number of fish per group $N(\mathrm{gr})$ were obtained by summing for all layers (2): 


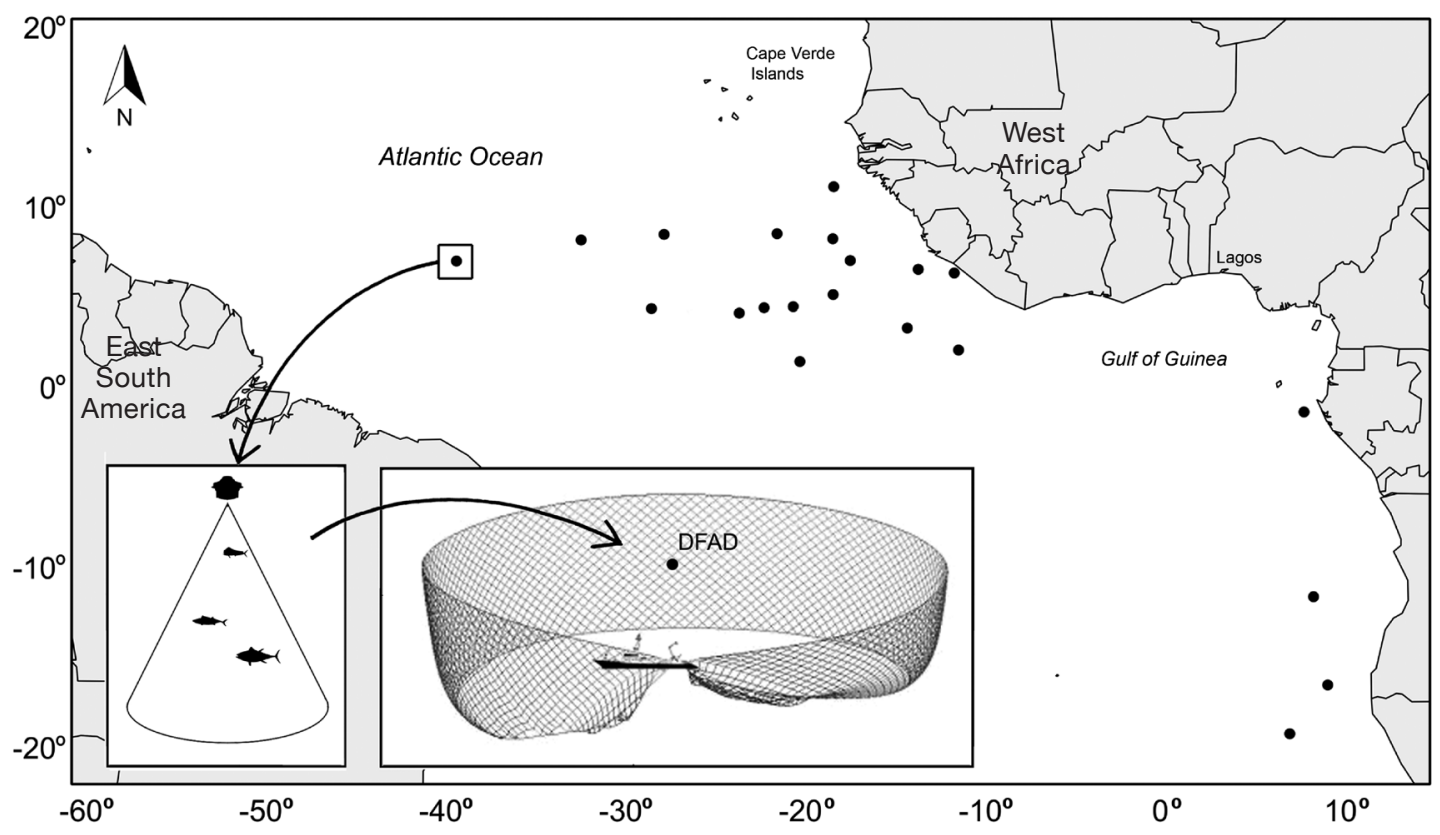

Figure 3

Map of the 21 locations $(\bullet)$ where echosounder buoy acoustic data and catch information were collected around drifting fish aggregating devices (DFADs). Acoustic samples were taken at sunrise and were followed by regular fishing sets to gather information on the size and composition of catch. Fishing sets were conducted by a commercial Spanish purse seiner in the central and eastern Atlantic Ocean between 2009 and 2011.

$$
N(\mathrm{gr})=\Sigma_{n} N(n, g r)
$$

The estimated number of fish per group $(N[\mathrm{gr}])$ was converted into biomass per group ( $B$ [gr], in t) by multiplying the total amount of individuals by their corresponding mean weight $(w$, in $\mathrm{kg}$ ) and dividing by 1000.

$$
B(g r)=\frac{N(g r) \cdot w(g r)}{1000}
$$

where $B(g r)=$ the biomass estimated per fish group (in $\mathrm{t})$;

$N(g r)=$ the number of individuals per group; and $w(g r)=$ the average weight of an individual of a particular group (in $\mathrm{kg}$ ) used to convert number of individuals in weight.

Finally, the total uncorrected predicted tuna biomass $\left(B_{\mathrm{u}}\right.$, in $\left.\mathrm{t}\right)$ is the sum of the biomass estimated for the two tuna categories (corresponding to the sum of depth layers 3-10), whereas total biomass of nontuna species is the estimate obtained for that specific group (sum of layers 1-2).

Parameter optimization Because vertical limits (depth boundaries) previously set may vary depending on the regional site, we used a set of 21 fishing sets to optimize our method and evaluate the depth limit selected for the particular case of the Atlantic Ocean. Additionally, the same set of catches was used in a further stage to adjust and correct biomass estimates of the new method (see next section).

Twenty-one acoustic samples collected from echosounder buoys between 2009 and 2011 in the central and eastern tropical Atlantic Ocean were used, along with their corresponding catch data, to make a first assessment of the performance of the proposed method (Fig. 3). Acoustic samples were collected at sunrise (i.e., the time of the day at which, according to the belief of fishermen, fish are supposed to be more concentrated under the DFAD) and were followed by regular fishing sets. We assumed purse seine catch to be a proxy for the total associated fish biomass at DFADs. Fishing operations were conducted by a Spanish purse seiner during conventional commercial fishing trips. Information on the species composition of the aggregation was then obtained in $\mathrm{t}$ and as commercial categories for each tuna species from the skipper's logbook.

In order to investigate the effect of the changes in the selection of the depth limit between small and large tunas for final biomass estimates, the echo-integration procedure was conducted repeatedly by applying all possible combinations to the depth limit between small and large tunas within the entire depth range (i.e., changing the virtual limit from $80 \mathrm{~m}$ to 92 $\mathrm{m}, 104 \mathrm{~m}, 115 \mathrm{~m}, 70 \mathrm{~m}, 59 \mathrm{~m}, 47 \mathrm{~m}, 36 \mathrm{~m}$, and 25 $\mathrm{m}$ ), with the exception of the first $25 \mathrm{~m}$, which were always considered inhabited mainly by nontuna species (Robert et al., 2013; Forget et al., 2015). For the 


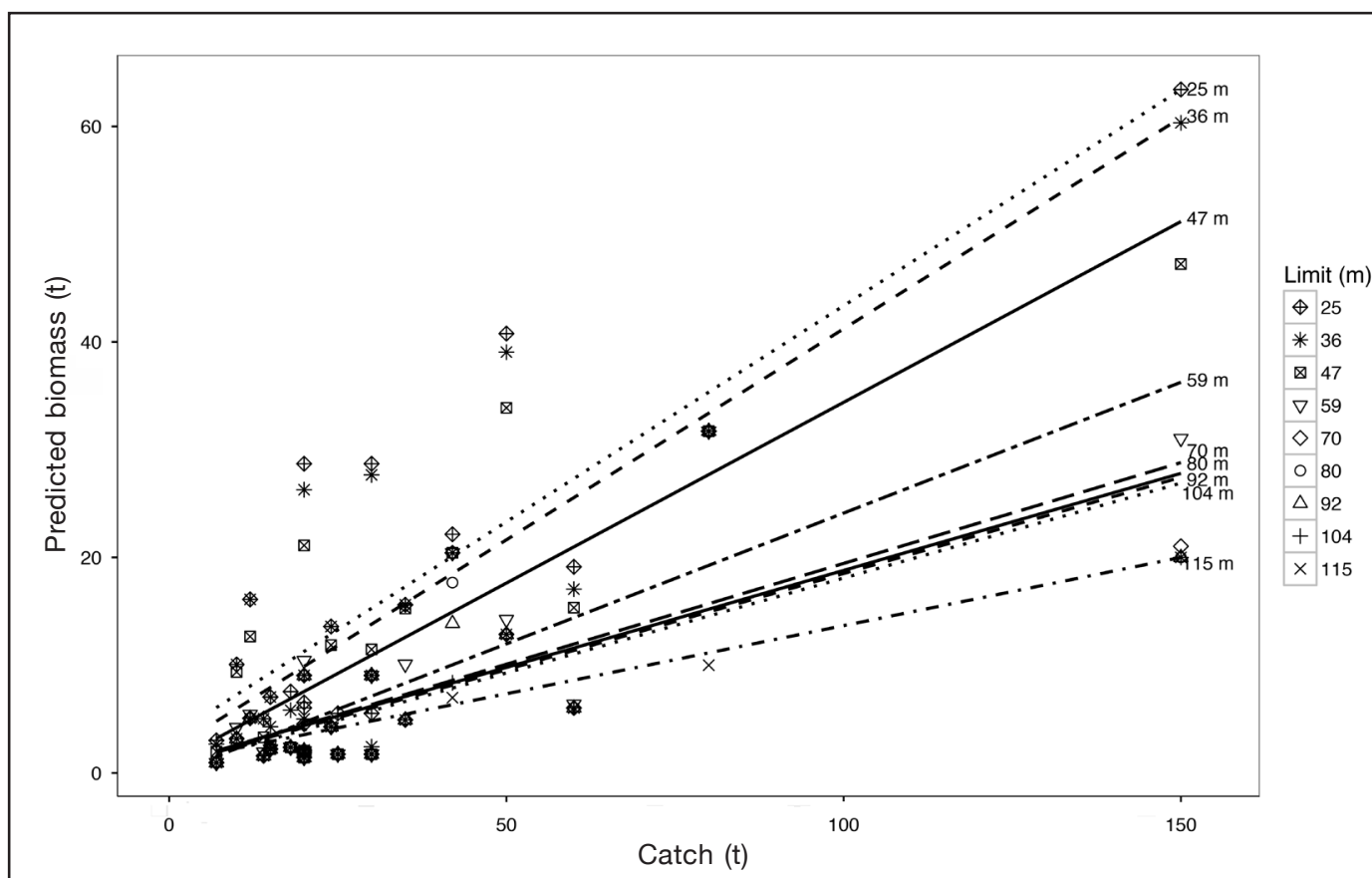

Figure 4

Linear relationships between uncorrected predicted biomasses, obtained from models with different depths to set the limits between small and large tunas, and the real catch for the 21 samples collected by a commercial Spanish purse seiner in the central and eastern Atlantic Ocean between 2009 and 2011. The coefficients of correlation and determination of these relationships were used to select the optimum depth limit between small and large tunas for the particular case of this study.

specific case of these 21 fishing sets in the Atlantic Ocean, the best values for coefficients of correlation $(r)$ and determination $\left(r^{2}\right)\left(r=0.85, r^{2}=0.73\right.$; Table 1, Fig. 4) provided by the optimization process led us to reconsider and modify the original selection of vertical depth limits. Because of a known potential overlap between species and fish sizes in the vertical depth zones and the higher number of small tuna than large tuna individuals occurring at DFADs, we opted to keep only the TS and weight values of small tunas for the whole depth range (i.e., corresponding to a depth limit of 115 $\mathrm{m}$ (Table 1 and Fig. 4). This is the more ecologically coherent choice because the presence of small tunas at DFADs usually exceeds $95 \%$ of the catch (Fonteneau et al., 2013), which was also supported by the proportion of small tunas found in our 21 fishing sets.

Defining an error function In order to reduce uncertainty and improve the accuracy of biomass estimation with the new method, the uncorrected predicted biomass was compared and calibrated to the 21 real catches. Error (in t) of the new method was modeled with different regression models (polynomials of order 2 and 3, generalized linear models [GLM], and generalized additive models [GAM]; Hastie and Tibshirani, [1990]; Venables and Dichmont, [2004]; Wood, [2006]) (Fig. 5) as a function of the uncorrected predicted biomass, which was corrected as follows:

$$
B_{\mathrm{c}}=B_{\mathrm{u}}-f\left(B_{\mathrm{u}}\right)+\varepsilon,
$$

where $B_{c}=$ the corrected predicted biomass;

$B_{u}=$ the uncorrected predicted biomass of the new method; and

$f\left(B_{u}\right)=$ the error modeled following different regression methods as a function of uncorrected predicted biomass $\left(f\left[B_{u}\right]=-0.318\right.$ $B_{u}{ }^{2}+0.9951 B_{u}-17.598$ for the polynomial of order $2 ; f\left[B_{u}\right]=-0.0346 B_{u}{ }^{3}+0.7223 B_{u}{ }^{2}-$ $6.7657 B_{u}-5.5385$ for the polynomial of order 3; $f\left[B_{u}\right]=-4.7605 B_{u}-3.0981$ for the GLM; and $f\left[B_{u}\right]=$ absolute error of $B_{u} \sim \mathrm{S}(B u)$ as a generic formula for the GAM. Note that no explicit expression for the estimated smooth terms (s) is available for GAMs (see Hastie and Tibshirani, 1990). For the GAM case, values used to correct $B_{u}$ were extracted by using the predict.gam function of the mgcv package (vers. 1.7.29); and $\mathcal{E}$ is the assumed error ( 0 in this case). All the regression models were fitted by using the mgcv package, vers. 1.7.29, for $\mathrm{R}$ software, vers.3.2.1 (R Core Team, 2015).

The prediction capacity of each model was measured by computing both $r$ and $r^{2}$ between the corrected predicted biomass and the 21 real catches, and by using 
the summary statistics of the absolute errors (Table 2).

\section{Results}

\section{Accuracy of estimated tuna biomass}

To evaluate the accuracy of both our methods and those of the manufacturer, corrected tuna biomass estimates obtained by each method were compared with the biomass estimates from the purse-seine catch on these 21 DFADs. The $r$ and $r^{2}$ and the main statistics of the errors for each corrected biomass estimates obtained through the different correction functions are shown in Table 2. Results showed that all the methods performed similarly, significantly improving the accuracy of prediction values compared with the manufacturer's method. Despite the similar values obtained for all the corrected predicted biomasses from the different regression models, the GAM corrected model was selected as the potential main model selection of this study on the basis of its statistical robustness and consistency (Wood, 2006). Table 3 and Figure 6 show the final biomass estimates and the boxplot of the distribution of the error for the manufacturer's method and the GAM-corrected method developed by the authors. Maximum biomass estimation error ranged from -69 to 101 $\mathrm{t}$ (median and standard deviation [SD] of $-4 \pm 33.9 \mathrm{t}$ ) for the manufacturer's method and from -30.12 to $24.80 \mathrm{t}$ (with a median and SD of $1.23 \pm 13.74$ t) for the GAM corrected method. Thus, the original error variability ( $\mathrm{SD}=33.9$ ) was significantly reduced by $\sim 60 \%(\mathrm{SD}=13.74)$ and the ranges of underestimation and overestimation were diminished by $\sim 55 \%$ and $\sim 75 \%$, respectively. Additionally, the original $r$ and $r^{2}$ values were also considerably improved from 0.50 and 0.25 to 0.90 and 0.82 , respectively.

\section{Nontuna biomass estimates}

Because the crew was conducting regular fishing trips with no observer, we could not use catch data on in situ nontuna species to test the accuracy of the predicted biomass for this group. However, the average value of non-

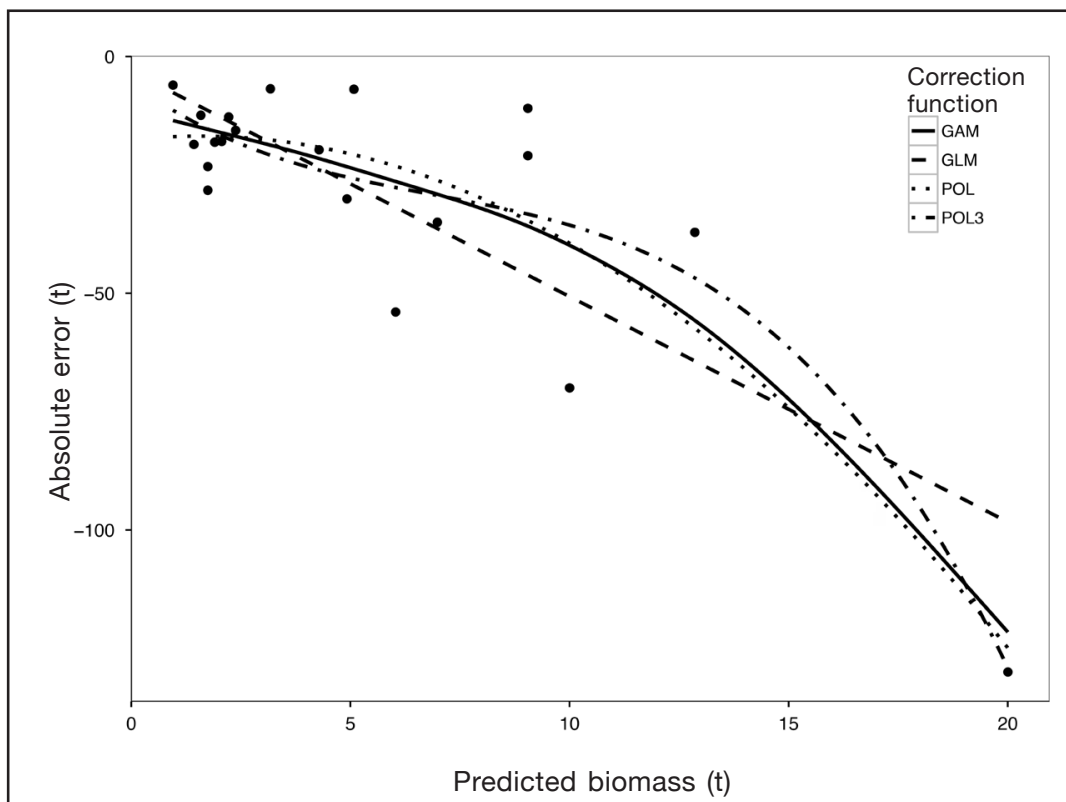

Figure 5

Regressions obtained through different methods (generalized additive model [GAM], generalized linear model [GLM], and polynomials of order 2 [POL] and 3 [POL3]) between uncorrected predicted biomass and absolute errors for the 21 samples collected by a commercial Spanish purse seiner in the central and eastern Atlantic Ocean between 2009 and 2011. Specific equations used in the present study are provided in the Defining an error function section. Regressions were used to correct and adjust the uncorrected biomass to the real catch.

\section{Table 2}

Summary statistics ( $\operatorname{med}=$ median; $\min =\operatorname{minimum} ; \max =\operatorname{maximum}$; $\mathrm{SD}=$ standard deviation) of the absolute errors (in metric tons [t]) for the final biomass estimations corrected through different regression models $(\mathrm{GLM}=$ generalized linear model; POL=polynomial of order 2; POL3=polynomial of order 3; GAM=generalized additive model) and the corresponding coefficients of correlation $(r)$ and determination $\left(r^{2}\right)$, when the statistics were compared with real catches.

\begin{tabular}{lcccccc}
\hline Error & $\begin{array}{c}\text { Before } \\
\text { correction }\end{array}$ & $\begin{array}{c}\text { Manu- } \\
\text { facturer }\end{array}$ & GLM & POL & POL3 & GAM \\
\hline med (t) & -18.57 & -4 & -1.18 & 0.54 & 2.18 & 1.23 \\
$\min (\mathrm{t})$ & -130 & -69 & -31.67 & -30.80 & -34.43 & -30.12 \\
$\max (\mathrm{t})$ & -6 & 101 & 35.23 & 23.68 & 22.30 & 24.80 \\
$\mathrm{SD}(\mathrm{t})$ & 28.22 & 33.87 & 16.77 & 13.96 & 13.38 & 13.74 \\
\hline Parameter & & & & & & \\
\hline$r$ & 0.85 & 0.50 & 0.85 & 0.90 & 0.91 & 0.90 \\
$r^{2}$ & 0.73 & 0.25 & 0.73 & 0.81 & 0.83 & 0.82 \\
\end{tabular}




\section{Table 3}

Absolute error (in metric tons, t), for biomass estimates ( $t$ ) and real catch (t), from each of the two methods analyzed in this study for 21 sets conducted by a commercial Spanish purse seiner in the Atlantic Ocean between 2009 and 2011. Shown also are the biomass estimates originally provided by the Satlink buoy (S) with the use of an algorithm based on skipjack (Katsuwonus pelamis) and the final biomass estimates obtained with the new method (NM) proposed in this study.

\begin{tabular}{|c|c|c|c|c|c|}
\hline Buoy code & $\begin{array}{l}\text { Catch } \\
\text { (t) }\end{array}$ & $\begin{array}{c}\text { Biomass } \\
\text { estimate } \\
(\mathrm{t})(\mathrm{S})\end{array}$ & $\begin{array}{l}\text { Absolute } \\
\text { error } \\
(\mathrm{t})(\mathrm{S})\end{array}$ & $\begin{array}{l}\text { Biomass } \\
\text { estimate } \\
\text { (t) }(\mathrm{NM})\end{array}$ & $\begin{array}{l}\text { Absolute } \\
\text { error } \\
\text { (t) }(\mathrm{NM})\end{array}$ \\
\hline 23753 & 20 & 12 & -8 & 17.66 & -2.34 \\
\hline 23728 & 24 & 8 & -16 & 25.84 & 1.84 \\
\hline 23737 & 10 & 20 & 10 & 21.90 & 11.90 \\
\hline 23825 & 150 & 81 & -69 & 141.58 & -8.42 \\
\hline 23737 & 20 & 121 & 101 & 44.88 & 24.88 \\
\hline 23825 & 14 & 10 & -4 & 16.60 & 2.60 \\
\hline 23751 & 60 & 38 & -22 & 32.43 & -27.57 \\
\hline 23750 & 50 & 84 & 34 & 68.60 & 18.60 \\
\hline 28171 & 18 & 16 & -2 & 19.23 & 1.23 \\
\hline 23736 & 35 & 31 & -4 & 28.21 & -6.79 \\
\hline 28179 & 25 & 11 & -14 & 17.13 & -7.87 \\
\hline 28184 & 80 & 63 & -17 & 49.88 & -30.12 \\
\hline 28643 & 42 & 106 & 64 & 36.09 & -5.91 \\
\hline 28471 & 30 & 17 & -13 & 17.13 & -12.87 \\
\hline 28707 & 15 & 14 & -1 & 18.71 & 3.71 \\
\hline 28697 & 12 & 32 & 20 & 28.81 & 16.81 \\
\hline 30528 & 7 & 2 & -5 & 14.48 & 7.48 \\
\hline 28390 & 20 & 11 & -9 & 16.07 & -3.93 \\
\hline 28216 & 15 & 14 & -1 & 18.71 & 3.71 \\
\hline 28705 & 30 & 59 & 29 & 44.88 & 14.88 \\
\hline 30530 & 20 & 16 & -4 & 18.18 & -1.82 \\
\hline
\end{tabular}

tuna species biomass per set was estimated at 0.627 $\mathrm{t}(\min =0 ; \max =12.398 ; \mathrm{SD}=2.37)$, which fitted reasonably well with the values found in the Atlantic Ocean for the European purse seine fleet (mean=0.79; $\min =0$; $\max =22.06)\left(\right.$ Amandé $\left.^{13}\right)$.

\section{Discussion}

Echosounder buoys are widely employed by the industrial tropical tuna purse seine fishery and their use has rapidly increased since their introduction into the market in the mid-to-late 2000s (Lopez et al., 2014). In fact, Baske et al. ${ }^{1}$ estimated an annual production of 50,000-70,000 satellite-tracked buoys by the major buoy-producing companies, of which most were fitted with echosounders. However, this source of information needs to be evaluated and validated before use in fisheries applications. We present a processing method that takes into account the multispecies and multisize nature of DFAD-associated aggregations. The method

\footnotetext{
${ }^{13}$ Amandé, M. J. 2012. Personal commun. Centre de Recherces Oceanologiques, CRO, 29, Rues des pecheurs, BP V 18, Abidjan, Cote d'Ivoire.
}

substantially improves the overall precision of the original biomass estimation (error variability and the ranges of underestimation and overestimation have been notably diminished) and also provides biomass data by major species groups, rather than a single information unit on the entire fish aggregation based only on one species of tuna (i.e., skipjack tuna).

\section{Echosounder buoys for scientific studies}

The method developed in the present study shows the potential for echosounder buoys as small autonomous tools that can provide information on fish aggregations at DFADs over weeks and months. Echosounder buoys attached to FADs could constitute ideal observational platforms, providing data on the fish community associated with floating objects. Monitoring of FAD buoy data could then provide a powerful tool for scientific evaluation of resource abundance and for improved knowledge of the associative behavior of the fish communities associated with FADs. In order to increase the sampling potential and data input, scientists should consider similar studies on the other echosounder buoy brands currently used by industrial purse-seine operators and which are not addressed in the present study. 


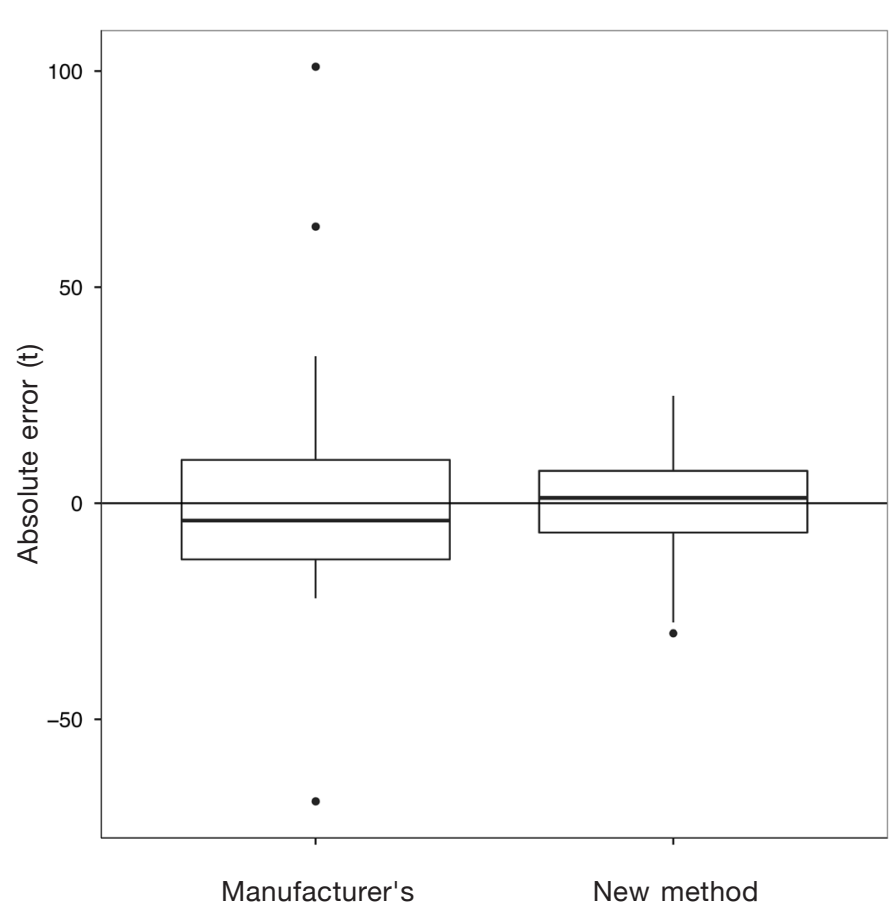

Figure 6

Error variability when converting acoustic backscatter into biomass by two different methods analyzed in the present work: the manufacturer's original method and the GAM corrected biomass estimations obtained with the new method developed in this study. Acoustic data and real catches were collected by a commercial Spanish purse seiner in the central and eastern Atlantic Ocean between 2009 and 2011 to illustrate the use of the new method. Black dots are outlier points. The box show the quartiles, with the bars extending to the most extreme data point which is no more than \pm 1.5 the interquartile range. The heavy line across the box is the median.

The new remote-target classification method opens a broad range of future lines of research in the area of FAD-related fish ecology and behavior. Because the model can group species, every acoustic sample given by the buoy could return specific biomass-index estimates for nontuna and tuna species. This raises the possibility of computing a wide range of statistical and mathematical analyses by fish group, such as modeling environmental preferences of each species and groups or estimating fish biomass fluctuations in relation to FAD trajectories, time of the day or soaking time, among other variables.

One of the most interesting and promising lines of investigation derived from this study is the possibility of obtaining fisheries-independent indices of relative abundance for tuna and nontuna species, a major and urgent challenge that would certainly complement current data on target and nontarget species populations. Significant effort has been recently conducted by fisheries scientists in this field, who have started to design the first promising steps to carry out this kind of study (Capello et al.14; Santiago et al.15).

\section{Sustainable fishing practices with echosounder buoys}

Nontuna biomass data provided by the new method, when validated by observational data in the specific regions of interest, may have at least two different applications for conservation issues. First, nontuna-to-tuna biomass ratios can be remotely estimated, helping fishing crews to avoid setting on undesirable DFADs with a high proportion of nontarget individuals. As Dagorn et al. (2012) suggested, the smaller the nontuna-to-tuna ratio, the lower are the impacts on nontarget species. In this context, echosounder buoys may contribute, from virtually unlimited distances, to the selection of the best DFAD to fish from a conservation point of view. Fishermen could benefit by saving fuel and time, optimizing their effort, catch and profits, by carefully planning their FAD-fishing routes in advance. Second, potential nontuna hotspots could be discovered, which could aid setting conservational measures, such as temporal or permanent marine protected areas or DFAD closures, if necessary. Hotspots obtained by this approach should be ground-truthed to those found through analysis of observer data, keeping in mind that the information of observers is based on fishing operations and hence, limited by fishing effort and fishing coverage constraints. Both sources of information should be, therefore, complementary. Although the nontuna biomass given by this study has not been specifically validated due to a lack of scientific biological sampling during the fishing operations used for testing the model, the results seem to be in accordance with values found by unpublished studies in the Atlantic Ocean (Amandé13). Future studies should take into account more detailed information on species composition (e.g., observers' data) to better understand the performance capability of this new method, especially in relation to nontuna species.

It is important to note that the original idea of this article was to include tuna size in the biomass estimation models, which would provide interesting informa-

\footnotetext{
${ }^{14}$ Capello, M., J.-L. Deneubourg, M. Robert, K. Holland, K. Schaeffer, and L. Dagorn.. 2013. A new fisheries independent method to estimate abundances of tropical tunas. Indian Ocean Tuna Commision (IOTC). Working Party Tropical Tuna (WPTT) IOTC-2013-WPTT15-12, 30 p. [Available at website.]

${ }^{15}$ Santiago, J., J. Lopez, G. Moreno, H. Murua, I. Quincoces, and M. Soto. 2015. Towards a tropical tuna buoy-derived abundance index (TT-BAI). International Council for the Conservation of Atlantic Tunas (ICCAT) SCRS/2015/90, 12 p. ICCAT, Corazón de María, 8, 28002 Madrid, Spain.
} 
tion on the relative presence of both small and large tunas at DFADs. However, and likely due to the limited catch sample and the high numbers of small tunas occurring in those catches (i.e., 95\%), the optimization process led us to keep a single group of tuna sizes for the whole vertical range. We expect that, by tuning and refining this method, by ocean or regional site and with greater amounts of data in the future, this approach will be able to remotely provide fishing crews and scientists with the potential proportion of different tuna sizes under a particular DFAD, with consequent fishing advantages and conservation applications.

\section{Model improvement}

Although FADs tend to standardize the vertical behavior of fish (Matsumoto et al.4; Taquet et al., 2007b; Leroy et al., 2009; Govinden et al.5; Matsumoto et al., 2012; Schaefer and Fuller, 2013), it seems likely that the main depths occupied by fish of different sizes and species may differ between oceans or regional sites. Because vertical behavior is likely affected by the oceanography of an area, future tagging experiments should cover unsampled locations and couple both simultaneous in situ environmental data recorders (i.e., CTD profile recorders or acoustic surveys with scientific echosounders) and acoustic telemetry. High quality and high resolution data would contribute to a better understanding of the effect of biotic and abiotic factors on the vertical behavior of fish species when associated with floating objects-research that is necessary to improve the interpretation of data from echosounder buoys.

The present study employs the TS values obtained by Moreno et al. (2007), which fit reasonably well with the preliminary vertical depth layers defined in this work and with the results of other studies (Josse and Bertrand, 2000; Josse et al., 2000; Doray et al., 2006; Doray et al., 2007). As is widely recognized, knowing the TS value of a species is of primary importance to properly transform acoustic backscatter into species biomass. However, TS of many FAD-associated species remains elusive. Further ex situ or in situ investigations coupling acoustics with other supplementary technologies, such as video-cameras or ROVS (i.e., remotely operated vehicles) would permit obtaining precise TS values by species and thus improve the accuracy of estimates at species levels. Nonetheless, species-specific biomass conversion seems to be difficult to achieve in the current scenario. As Handegard et al. (2012) stated, one of the major challenges associated with acoustic measurements on autonomous platforms is the lack of biological sampling to verify the taxonomic composition. One possible solution to solve this situation is to explore catch variability and obtain spatiotemporal patterns of species composition at DFADs. Results could be used in future experiments to improve the performance of the method by postprocessing actual biomass estimates in cases where no biological sampling is available.

Although the echosounder buoys used in this study were developed for fishing purposes, there is still much room to improve the technical and technological features of current echosounder buoys. Ideally, some technical issues such as the lack of regular calibrations of the transducers or the characterization of their vertical and angular detection ranges should be solved. These are complicated issues due to the large number of echosounders (thousands of each brand) that are deployed with DFADs each year globally. A compromise solution could be the calibration of a limited number of transducers of each brand along an extended period of time, long enough to model a general calibration factor as a function of time. If consistent, the obtained brand-specific function could be then applied to all transducers, replacing the need to calibrate each transducer for every period of time. These calibrations could also include detectability functions at different depth ranges and angles in order to characterize the vertical and angular detection ranges of the transducer as a function of the TS of the targets. Then, the obtained detectability functions could be applied by using distance-sampling techniques (Buckland et al., 1993). Similarly, the range of the echosounder system, operation frequency, split beam technology, etc. should also be re-examined, optimized, installed, and adapted to the presence of different tropical tuna and accompanying nontuna species. Therefore, continuous improvements would be possible in the successive releases of new generations of transducers. For example, the recent inclusion of multifrequency transducers in two echosounder buoy brands could enable improved species discrimination in the near future, although those transducers would also require improved algorithms for analysis.

Due to confidentiality and sensitive issues, the flow of echosounder buoy data from vessel owners to research institutes is still rare. A data exchange system that preserves the privacy and ensures future bilateral advantages could help in effective industry and science collaboration. These kinds of initiatives should be endorsed by international bodies (e.g., tuna regional fisheries management organizations) to guarantee the viability of a project for both industry and science and to help promote such studies with an aim toward maintaining the long-term sustainability of fisheries.

\section{Acknowledgments}

The authors sincerely thank all the fishing masters from the Spanish tuna purse-seiner fleet who kindly agreed to answer our questions. We would like to thank the Spanish ship-owners and the associations that represent them (Asociación Nacional de Armadores de Buques Atuneros Congeladores [ANABAC] and Organización de Productores Asociados de Grandes Atuneros Congeladores [OPAGAC]). Of course we would like to thank the buoy manufacturers that provide us with technical data on their echosounder buoys. We sincerely thank G. P. Scott for revising the English and for useful comments that considerably improved this 
article. This study was part of the European project MADE (Mitigating adverse ecological impacts of open ocean fisheries), funded by DG Research (Collaborative Project $\mathrm{n}^{\circ}$ 210496). This article is contribution no. 751 from AZTI-Tecnalia. This study was partly funded by a PhD grant by the Fundación Centros Tecnológicos Iñaki Goenaga to Jon Lopez.

\section{Literature cited}

Babaran, R., C. Endo, Y. Mitsunaga, and K. Anraku. 2009. Telemetry study on juvenile yellowfin tuna Thunnus albacares around a payao in the Philippines. Fish. Eng. (Jpn) 46:21-28.

Brill, R. W., B. A. Block, C. H. Boggs, K. A. Bigelow, E. V. Freund, and D. J. Marcinek.

1999. Horizontal movements and depth distribution of large adult yellowfin tuna (Thunnus albacares) near the Hawaiian Islands, recorded using ultrasonic telemetry: implications for the physiological ecology of pelagic fishes. Mar. Biol. 133:395-408. Article

Buckland, S. T., D. R. Anderson, K. P. Burnham, and J. L. Laake.

1993. Distance sampling: estimating abundance of biological populations, 446 p. Chapman and Hall, London.

Castro, J. J., J. A. Santiago, and A. T. Santana-Ortega.

2002. A general theory on fish aggregation to floating objects: an alternative to the meeting point hypothesis. Rev. Fish Biol. Fish. 11:255-277. Article

Dagorn, L., K. Holland, J. Dalen, P. Brault, C. Vrignaud, E. Josse, G. Moreno, P. Brehmer, L. Nottestad, S. Georgakarakos, V. Trigonis, M. Taquet, R. Aumeeruddy, C. Girard, D. Itano, and G. Sancho.

2007a. New instruments to observe pelagic fish around FADs: satellite-linked acoustic receivers and buoys with sonar and cameras. In Cutting-edge technologies in fish and fisheries science. Australian Society for Fish Biology Workshop Proceedings; Hobart, Tasmania, Australia, 28-29 August 2006 (J. M. Lyle, D. M. Furlani, and C. D. Buxton, eds.), p. 37-43. Australian Soc. Fish Biol., Hobart, Tasmania, Australia.

Dagorn, L., K. N. Holland, and D. G. Itano.

2007b. Behavior of yellowfin (Thunnus albacares) and bigeye ( $T$. obesus) tuna in a network of fish aggregating devices (FADs). Article

Dagorn, L., D. Pincock, C. Girard, K. Holland, M. Taquet, G. Sancho, D. Itano, and R. Aumeeruddy.

2007c. Satellite-linked acoustic receivers to observe behavior of fish in remote areas. Aquat. Living Resour. 20:307-312. Article

Dagorn, L., J. D. Filmalter, F. Forget, M. J. Amandè, M. A. Hall, P. Williams, H. Murua, J. Ariz, P. Chavance, and N. Bez.

2012. Targeting bigger schools can reduce ecosystem impacts of fisheries. Can. J. Fish. Aquat. Sci. 69:1463-1467. Article

Dagorn, L., K. N. Holland, V. Restrepo, and G. Moreno.

2013. Is it good or bad to fish with FADs? What are the real impacts of the use of drifting FADs on pelagic marine ecosystems? Fish Fish. 3:391-415. Article
Doray, M., E. Josse, P. Gervain, L. Reynal, and J. Chantrel. 2006. Acoustic characterisation of pelagic fish aggregations around moored fish aggregating devices in Martinique (Lesser Antilles). Fish. Res. 82:162-175. Article

Doray, M., E. Josse, P. Gervain, L. Reynal, and J. Chantrel. 2007. Joint use of echosounding, fishing and video techniq ues to assess the structure of fish aggregations around moored fish aggregating devices in Martinique (Lesser Antilles). Aquat. Living Resour.20:357-366. Article

Filmalter, J. D., L. Dagorn, P. D. Cowley, and M. Taquet. 2011. First descriptions of the behavior of silky sharks, Carcharhinus falciformis, around drifting fish aggregating devices in the Indian Ocean. Bull. Mar. Sci. 87:325-337. Article

Fonteneau, A., E. Chassot, and N. Bodin.

2013. Global spatio-temporal patterns in tropical tuna purse seine fisheries on drifting fish aggregating devices (DFADs): taking a historical perspective to inform current challenges. Aquat. Living Resour. 26:37-48. Article

Forget, F. G., M. Capello, J. D. Filmalter, R. Govinden, M. Soria, P. D. Cowley, L. Dagorn.

2015. Behaviour and vulnerability of target and nontarget species at drifting fish aggregating devices (FADs) in the tropical tuna purse seine fishery determined by acoustic telemetry. Can. J. Fish. Aquat. Sci. 72:1398-1405. Article

Govinden, R., R. Jauhary, J. Filmalter, F. Forget, M. Soria, S. Adam, and L. Dagorn.

2013. Movement behaviour of skipjack (Katsuwonus pelamis) and yellowfin (Thunnus albacares) tuna at anchored fish aggregating devices (FADs) in the Maldives, investigated by acoustic telemetry. Aquat. Living Resour. 26:69-77. Article

Handegard, N. O., L. Buisson, P. Brehmer, S. J. Chalmers, A. De Robertis, G. Huse, R. Kloser, G. Macaulay, O. Maury, P. H. Ressler, N. C. Stenseth, and O. R. Godø.

2012. Towards an acoustic-based coupled observation and modelling system for monitoring and predicting ecosystem dynamics of the open ocean. Fish Fish. 4:605-615. Article

Hastie, T. J., and R. J. Tibshirani.

1990. Generalized additive models. Monogr. Stat. Appl. Probability 43, 335 p. Chapman and Hall/CRC, London.

IATTC (Inter-American Tropical Tuna Commission).

2013. Tunas and billfishes in the eastern Pacific Ocean in 2012. IATTC Fish. Status Rep. 11, 171 p. [Available at website.]

Josse, E., P. Bach, and L. Dagorn.

1998. Simultaneous observations of tuna movements and their prey by sonic tracking and acoustic surveys. Hydrobiologia 371:61-69. Article

Josse, E., and A. Bertrand.

2000. In situ acoustic target strength measurements of tuna associated with a fish aggregating device. ICES J. Mar. Sci. 57:911-918. Article

Josse, E., L. Dagorn, and A. Bertrand.

2000. Typology and behaviour of tuna aggregations around fish aggregating devices from acoustic surveys in French Polynesia. Aquat. Living Resour. 13:183-192. Article

Leroy, B., D. G. Itano, T. Usu, S. J. Nicol, K. N. Holland, and J. Hampton.

2009. Vertical behavior and the observation of FAD effects on tropical tuna in the warm-pool of the western Pacific Ocean. In Tagging and tracking of marine ani- 
mals with electronic devices (J. L. Nielsen, H. Arrizabalaga, N. Fragoso, A. Hobday, M. Lutcavage, and J. Sibert, eds.), p. 161-179. Springer Netherlands, Dordrecht, the Netherlands.

Lopez, J., G. Moreno, I. Sancristobal, and J. Murua.

2014. Evolution and current state of the technology of echo-sounder buoys used by Spanish tropical tuna purse seiners in the Atlantic, Indian and Pacific Oceans. Fish. Res. 155:127-137. Article

MacLennan, D. N., P. G. Fernandes, and J. Dalen.

2002. A consistent approach to definitions and symbols in fisheries acoustics. ICES J. Mar. Sci. 59:365-369. Article

Matsumoto, T., T. Kitagawa, and S. Kimura.

2012. Considerations on diving patterns of bigeye tuna Thunnus obesus based on archival tag data. Fish. Sci. 79:39-46. Article

Matsumoto, T., K. Satoh, and M. Toyonaga.

2014. Behavior of skipjack tuna (Katsuwonus pelamis) associated with a drifting FAD monitored with ultrasonic transmitters in the equatorial central Pacific Ocean. Fish. Res. 157:78-85. Article

Maufroy, A., E. Chassot, R. Joo, and D. M. Kaplan.

2015. Large-scale examination of spatio-temporal patterns of drifting fish aggregating devices (dFADs) from tropical tuna fisheries of the Indian and Atlantic Oceans. PLoS ONE. 10(5):e0128023. Article

Mitsunaga, Y., C. Endo, K. Anraku, C. M. Selorio Jr., and R. P. Babaran.

2012. Association of early juvenile yellowfin tuna Thunnus albacares with a network of payaos in the Philippines. Fish. Sci. 78:15-22. Article

Moreno, G., E. Josse, P. Brehmer, and L. Nøttestad.

2007. Echotrace classification and spatial distribution of pelagic fish aggregations around drifting fish aggregating devices (DFAD). Aquat. Living Resour. 20:343-356. Article

Musyl, M. K., R. W. Brill, C. H. Boggs, D. S. Curran, T. K. Kazama, and M. P. Seki.

2003. Vertical movements of bigeye tuna (Thunnus obesus) associated with islands, buoys, and seamounts near the main Hawaiian Islands from archival tagging data. Fish. Oceanogr. 12:152-169. Article

$\mathrm{R}$ Core Team.

2015. R: a language and environment for statistical com- puting. R Foundation for Statistical Computing, Vienna, Austria. [Available from website, accessed July 2015.]

Robert, M., L. Dagorn, J. Lopez, G. Moreno, and J.-L. Deneubourg.

2013. Does social behavior influence the dynamics of aggregations formed by tropical tunas around floating objects? An experimental approach. J. Exp. Mar. Biol. Ecol. 440:238-243. Article

Schaefer, K. M., and D. W. Fuller.

2005. Behavior of bigeye (Thunnus obesus) and skipjack (Katsuwonus pelamis) tunas within aggregations associated with floating objects in the equatorial eastern $\mathrm{Pa}$ cific. Mar. Biol. 146:781-792. Article

2013. Simultaneous behavior of skipjack (Katsuwonus pelamis), bigeye (Thunnus obesus), and yellowfin (T. albacares) tunas, within large multi-species aggregations associated with drifting fish aggregating devices (FADs) in the equatorial eastern Pacific Ocean. Mar. Biol 160:3005-3014. Article

Simmonds, J., and D. N. MacLennan.

2005. Fisheries acoustics: theory and practice, 2nd ed., 437 p. Blackwell Science, London.

Taquet, M., L. Dagorn, J.-C. Gaertner, C. Girard, R. Aumerruddy, G. Sancho, and D. Itano.

2007a. Behavior of dolphinfish (Coryphaena hippurus) around drifting FADs as observed from automated acoustic receivers. Aquat. Living Resour. 20:323-330. Article

Taquet, M., G. Sancho, L. Dagorn, J.-C. Gaertner, D. Itano, R. Aumeeruddy, B. Wendling, and C. Peignon.

2007b. Characterizing fish communities associated with drifting fish aggregating devices (FADs) in the Western Indian Ocean using underwater visual surveys. Aquat. Living Resour. 20:331-341. Article

Venables, W. N., and C. M. Dichmont.

2004. GLMs, GAMs and GLMMs: an overview of theory for applications in fisheries research. Fish. Res. 70:319-337. Article

Weng, J.-S., M.-K. Hung, C.-C. Lai, L.-J. Wu, M.-A. Lee, and K.-M. Liu.

2013. Fine-scale vertical and horizontal movements of juvenile yellowfin tuna (Thunnus albacares) associated with a subsurface fish aggregating device (FAD) off southwestern Taiwan. J. Appl. Ichthyol. 29:990-1000. Article

Wood, S.

2006. Generalized additive models: an introduction with R, 410 p. Chapman and Hall/CRC, London. 